\title{
Incidence of Lead System Malfunction Detected During Implantable Defibrillator Generator Replacement
}

\author{
RAJIVA GOYAL, MARK HARVEY, LAURA HORWOOD, FRANK BOGUN, \\ MARK CASTELLANI, K.K. CHAN, EMILE DAOUD, MARK NIEBAUER, \\ K. CHING MAN, FRED MORADY, and S. ADAM STRICKBERGER
}

From the Division of Cardiology, Department of Internal Medicine, University of Michigan Medical Center, Ann Arbor, Michigan

GOYAL, R., ET AL.: Incidence of Lead System Malfunction Detected During Implantable Defibrillator Generator Replacement. Implantable cardioverter-defibrillator (ICD) generator replacement due to a depleted battery is a frequently performed procedure. The frequency with which sensing and defibrillation system failures are identified during device replacement procedures has not been previously described. Therefore, the purpose of this study was to prospectively determine the frequency of lead system malfunction detected at the time of device replacement in 55 consecutive patients undergoing ICD generator replacement. The mean age of the patients was $63 \pm 10$ years and 40 of them were men. Forty-nine patients had an epicardial lead system, and six patients had a nonthoracotomy lead system. Four (7\%) of these 55 patients were noted to have previously undetected lead system failure, either sensing $(n=3)$ or defibrillation $(n=1)$, necessitating system revision. The lead systems that failed were $40 \pm 6$ months old (33-49 months). In summary, during ICD generator replacement, previously undetected problems with sensing or defibrillation may be identified in approximately $10 \%$ of patients. Therefore, a comprehensive evaluation of the sensing and the defibrillation functions should be an essential component of the ICD generator replacement procedure. (PACE 1996; 19:1143-1146)

sudden cardiac death, ventricular tachycardia, ventricular fibrillation

\section{Introduction}

The utility of implantable cardioverter-defibrillators (ICDs) to protect against sudden cardiac death has been well established. ${ }^{1-5}$ As the number of patients with ICDs has increased, so has the number of patients with devices that have developed battery depletion and require a generator replacement. The frequency with which defibrillation and sensing system failures are identified during generator replacement procedures has not previously been reported. Therefore, the purpose of this study was to determine the value of complete lead system assessment at the time of ICD replacement.

Address for reprints: S. Adam Strickberger, M.D., Division of Cardiology, University of Michigan Medical Center, 1500 East Medical Center Dr., Ann Arbor, MI 48109-0022. Fax: (313) 9367026.

Received March 10, 1995; revision April 17, 1995; accepted May 31, 1995.

\section{Methods}

\section{Patient Characteristics}

The patient population consisted of 55 consecutive patients undergoing an ICD generator replacement between October 1993 and November 1994. One of the patients herein presented had elevated defibrillation energy requirements (DER) and has been reported elsewhere. ${ }^{6}$ The mean age of the patients was $63 \pm 10$ years, 40 males and 15 females. Forty-three patients had coronary artery disease, 7 had idiopathic dilated cardiomyopathy, 3 had other forms of cardiomyopathy, and 2 had structurally normal hearts. The mean left ventricular ejection fraction was $0.29 \pm 0.10$. Thirty-five of the 55 patients presented with a cardiac arrest, 16 presented with ventricular tachycardia, and 4 presented with syncope. Forty-nine patients had an epicardial lead system, and 6 patients had a nonthoracotomy lead system (CPI Endotak System, model 0064; [Cardiac Pacemakers Inc., St. 
Paul, MN, USA] 2 patients also required a subcutaneous patch, model 0063). The epicardial defibrillation system was composed of two epicardial patches, and two screw-in sensing leads. The epicardial patches were always manufactured by the ICD manufacturer. The same was true of the sensing leads, except that 23 patients with a CPI system received Daig Corporation sensing leads (model 501170, Minneapolis, MN, USA). The initial ICD was manufactured by Cardiac Pacemakers, Inc. (CPI, St. Paul, MN, USA) in 49 patients, by Intermedics, Inc. (Engleton, TX, USA) in 4 patients, and by Medtronic, Inc. (Minneapolis, MN, USA) in 2 patients. The mean number of years from ICD implant to ICD generator replacement was $38 \pm 7$ months (28-48 months).

\section{Routine ICD Follow-Up}

All patients underwent routine outpatient ICD evaluation of the sensing lead every 3 months by one of the investigators. Sensing function was assessed with a beep-o-gram for CPI devices, or with real-time telemetry and $\mathrm{R}$ wave $(\mathrm{mV})$ assessment for Intermedics and Medtronic devices.

\section{ICD Generator Replacement}

ICD generator replacement was performed when the battery status indicated, as recommended by the manufacturer. At the time of ICD generator replacement, the patients were brought to the electrophysiology laboratory in a postabsorptive and unsedated state. Each patient signed an informed consent prior to all procedures. The site of the generator was inspected under fluoroscopy, to localize the header and its relative position to the lead(s). Sedation for the procedure was achieved with a combination of intravenous benzodiazepines and opiates. After infiltration with local anesthetic, an incision was made at the site of the previous scar. Using blunt dissection, the old generator was extracted and then disconnected from the leads. After demonstration of adequate defibrillation and sensing function, a new device was implanted, the pocket was irrigated with a gentamicin solution, and the incision was closed.

Replacement generators from CPI, Intermedics, Inc., Medtronic, Inc., and Ventritex (Sunnyville, CA, USA) were used. A CPI device (model
$1555,1600,1625,1700,1705$, or 1715$)$ was implanted in 45 patients, an Intermedics RES-Q (model 101-01) was implanted in 5 patients, a Medtronic PCD (model 7217B) was implanted in 2 patients, and a Ventritex V110C was implanted in 3 patients.

\section{Assessment of Sensing Lead Function}

After extraction of the ICD and disconnection of the leads from the ICD, the sensing leads were visually examined for a breach of insulator integrity. The pacing threshold and lead impedance were measured. If the insulation of the sensing lead was observed to have failed, or if the pacing threshold was $>5 \mathrm{~V}$, or the lead impedance was $>$ $1000 \Omega$, the lead was considered to be defective.

\section{Defibrillation Energy Requirement Determination}

An adequate DER was defined as at least $10 \mathrm{~J}$ less than the maximum output of the ICD. Ventricular fibrillation was induced using alternating current, and 10 seconds later a $20 \mathrm{~J}$ shock was delivered. If ventricular fibrillation was converted to sinus rhythm, an additional successful defibrillation at the same or less energy was required to demonstrate an adequate DER. Defibrillation was also tested with the device to ensure proper function. If the initial 20-J shock was unsuccessful, then $25 \mathrm{~J}$ was used during the subsequent induction of ventricular fibrillation.

\section{Statistical Analysis}

Continuous variables are expressed as the mean $\pm 1 \mathrm{SD}$.

\section{Results}

\section{Major Findings}

The ICD system was noted to be intact in 51 of the 55 patients. The mean DER at the time of ICD replacement was $16 \pm 7 \mathrm{~J}(5-25 \mathrm{~J})$. Lead system failures were identified in 4 of the 55 patients, 40 \pm 6 months after lead system implantation (33-49 months). Sensing lead failure was identified in three patients during the device replacement procedure, and failure to defibrillate was identified in 
one patient during assessment of the DER at the time of ICD generator replacement, $40 \pm 7$ months (33-49 months), and 41 months, respectively, after lead system implantation.

\section{Sensing or Defibrillation System Failure}

In three patients with an epicardial lead system, a sensing lead failure (model 501170, Daig Corp., Minnetonka, MN, USA) was detected when the defibrillator pocket was opened in the electrophysiology laboratory and the sensing lead evaluated. In addition to the identification of oversensing in all of these patients, a high impedance ( $>$ 1000) was demonstrated in 2 patients, a pacing threshold of $>5 \mathrm{~V}$ was observed in 3 patients, and a visually apparent loss of insulator integrity was noted in 1 patient. All three patients subsequently underwent an uncomplicated sensing lead replacement with an endocardial lead via the subclavian vein.

In one patient, an elevated DER was noted during the replacement procedure with a monophasic shock that was identical to the original waveform. An adequate DER was achieved when the original ICD was replaced without complication using a biphasic device (CPI model 1625).

\section{Discussion}

This study demonstrates that approximately $10 \%$ of patients undergoing ICD generator replacement due to battery depletion may be found to have a previously undetected sensing or defibrillation system failure. The usefulness of the beep-o-gram to detect a sensing problem has been previously reported. ${ }^{6,7}$ In this series, a clinically

\section{References}

1. Edel TB, Maloney JD, Moore S, et al. Six-year clinical experience with automatic implantable cardioverter defibrillator. PACE 1991; 14:1850-1854.

2. Kelly PA, Cannom DS, Garan H, et al. The automatic implantable cardioverter defibrillator: Efficacy, complications and survival in patients with malignant ventricular arrhythmias. J Am Coll Cardiol 1988; 11:1278-1286.

3. Gabry MD, Brodman R, Johnston D, et al. Automatic implantable cardioverter defibrillator: $\mathrm{Pa}-$ undetected sensing lead abnormality was identified in three patients by direct evaluation of the lead at the time of device replacement, despite routine device surveillance.

Lead fractures of epicardial and nonthoracotomy lead systems have been reported. ${ }^{8-16}$ However, in these previous reports, the fractures were usually discovered because of inappropriate shocks or during the course of routine followup. ${ }^{8-17}$ The data from the present study are the first data to suggest the importance of lead system assessment during generator replacement.

In one patient in the present report, the DER was noted to be unacceptably elevated 41 months after implantation with an epicardial defibrillator system. While energy requirements with an epicardial lead system are not thought to change chronically, ${ }^{18}$ an elevation in the DER may occur at least during the first 6 months after a nonthoracotomy lead system is implanted. ${ }^{19}$ The results of this study may not be generalizable to replacement of ICDs in patients with nonthoracotomy lead systems, although failure of nonthoracotomy lead systems can also develop over time. ${ }^{13-16}$ Together, the results of prior and present studies suggest that DER testing should be performed during generator replacement.

\section{Clinical Implications}

Sensing lead function and defibrillation efficacy should be carefully evaluated prior to and during the replacement procedure. Evaluation of lead system integrity may not be complete with a noninvasive evaluation, and therefore, both defibrillation and sensing functions should be appropriately evaluated at the time of ICD generator replacement. 
chronic defibrillation energy requirements necessitating implantable defibrillator lead system revision. PACE (In press).

7. Ballas SJ, Rashidi R, McAlister $\mathrm{H}$, et al. The use of beep-o-grams in the assessment of automatic implantable cardioverter defibrillator sensing function. PACE 1989; 12:1737-1745.

8. Echt DS, Armstrong K, Schmidt P, et al. Clinical experience, complications and survival in 70 patients with the automatic implantable cardioverter/defibrillator. Circulation 1985; 71:289-296.

9. Marchlinski FE, Flores BT, Buxton AE, et al. The automatic implantable cardioverter-defibrillator: Efficacy, complications, and device failures. Ann Intern Med 1986; 104:481-488.

10. Kelly PA, Cannom DS, Garan H, et al. The automatic implantable cardioverter-defibrillator: Efficacy, complications and survival in patients with malignant ventricular arrhythmias. J Am Coll Cardiol 1988; 11:1278-1286.

11. Winkle RA, Mead RH, Ruder MA, et al. Long-term outcome with the automatic implantable cardioverter-defibrillator. J Am Coll Cardiol 1989; 6:1353-1361.

12. Tullo NG, Saksena S, Krol RB, et al. Management of complications associated with a first-generation endocardial defibrillation lead system for implantable cardioverter-defibrillators. Am J Cardiol 1990; 66:411-415.
13. Epstein AE, Shepard RB. Failure of one conductor in a nonthoracotomy implantable defibrillator lead causing inappropriate sensing and potentially ineffective shock delivery. PACE 1993; 16(1):769-800.

14. Bardy GH, Hofer B, Johnson G, et al. Implantable transvenous cardioverter-defibrillators. Circulation 1993; 87:1152-1168.

15. Stambler BS, Wood MA, Damiano RJ, et al. Sensing/pacing lead complications with a newer generation implantable cardioverter-defibrillator: Worldwide experience from the guardian ATP 4210 clinical trial. J Am Coll Cardiol 1994; 23:123-132.

16. Strickberger SA, Hummel JD, Daoud E, et al. Implantation by electrophysiologists of 100 consecutive cardioverter defibrillators with nonthoracotomy lead systems. Circulation 1994; 90:868-872.

17. Daoud EG, Kirsh MM, Bolling SF, et al. Incidence, presentation, diagnosis, and management of malfunctioning implantable cardioverter-defibrillator rate-sensing leads. Am Heart J 1994; 128(5): 892-895.

18. Wetherbee JN, Chapman PD, Troup PJ, et al. Long term internal cardiac defibrillation threshold stability. PACE 1989; 12:443-450.

19. Venditti FJ Jr., Martin DT, Vassolas G, et al. Rise in chronic defibrillation thresholds in nonthoracotomy implantable defibrillator. Circulation 1994; 89(1):216-223. 
This document is a scanned copy of a printed document. No warranty is given about the accuracy of the copy. Users should refer to the original published version of the material. 